\title{
Novas metodologias na didática da Economia e Contabilidade - caso do Mestrado em Ensino Porfuguês
}

\section{Resumo}

Ana Luísa Rodrigues

Luísa Cerdeira

Universidade de Lisboa

Este estudo objetivou analisar o desenvolvimento de novas metodologias, designadamente a aplicação da Formação Ativa, no ensino de disciplinas do Mestrado em Ensino de Economia e de Contabilidade português, tendo em linha de conta as percepções dos futuros professores sobre o que é (ou deverá) ser Professor(a) de Economia e de Contabilidade. A metodologia de investigação utilizada foi a de estudo de caso, com observação participante, numa abordagem predominantemente qualitativa, suportada na investigação da própria prática, procurando caminhos para a inovação dos processos educativos em face do novo paradigma tecnológico contemporâneo. Foi constatada a aplicabilidade da Formação Ativa e obtidos resultados que verificaram a sua eficácia no ensino da Economia e Contabilidade, com 34 o desenvolvimento de metodologias de aprendizagem ativas, que se pretende que contribuam para o desenvolvimento pessoal e profissional docente na futura sociedade do conhecimento.

Palavras-chave: Metodologias de ensino. Formação ativa. Didática da Economia e da Contabilidade.

\section{New methodologies in Economics and Accounting education - case of Portuguese Teaching Master}

\section{Abstract}

The objective of this study was to analyze the development of new methodologies, namely the application of Active Training, in the teaching of subjects of the Portuguese Master in Teaching Economics and Accounting, considering the perceptions of future teachers about what is (or should be) Be a Professor of Economics and Accounting. The research methodology used was a case study, with participant observation, in a predominantly qualitative approach, supported in the investigation of the practice itself, looking for ways to innovate the educational processes facing the new contemporary technological paradigm. The applicability of the Active Training was verified and obtained results that verified its effectiveness in the teaching of Economics and Accounting, with the 
development of active learning methodologies, which are intended to contribute to personal and professional development of teachers in the future knowledge society.

Keywords: Teaching methodologies. Active training. Economics and accounting education.

\section{Nuevas metodologías en la didáctica de Economía y Contabilidad - caso del Máster en enseñanza Portugués}

\section{Resumen}

Este estudio objetivó analizar el desarrollo de nuevas metodologías, en particular la aplicación de la Formación Activa, en la enseñanza de disciplinas del Máster en Enseñanza de Economía y de Contabilidad portugués, teniendo en cuenta las percepciones de los futuros profesores sobre lo que es (y, o debe ser) ser Profesor(a) de Economía y de Contabilidad. La metodología de investigación utilizada fue la de estudio de caso, con observación participante, en un abordaje predominantemente cualitativo, apoyado en la investigación de la propia práctica, buscando caminos para la innovación de los procesos educativos frente al nuevo paradigma tecnológico contemporáneo. Se constató la aplicabilidad de la Formación Activa y se obtuvieron resultados que verificaron su eficacia en la enseñanza de la Economía y la Contabilidad, con el desarrollo de metodologías de aprendizaje activas, que se pretende que contribuyan al desarrollo personal y profesional docente en la futura sociedad del conocimiento.

Palabras clave: Metodologías de enseñanza. Formación activa. Didáctica de economía y contabilidad.

\section{Introdução}

interesse pela investigação, no âmbito da didática da Economia e da Contabilidade, é relativamente recente e carece ainda de forte desenvolvimento, e, segundo Miranda, Nova e Bruno Júnior (2012), se verifica, igualmente, em Portugal. Acresce que alguns estudos, realizados no Brasil, mostram que a vertente pedagógica, nomeadamente, na formação inicial do professor de contabilidade é muito reduzida e está aquém do necessário, e ainda, se denota ausência da dimensão humana, em prol da técnica, na análise dos conteúdos.

Também Slomski, Lames, Megliorini e Lames (2013) referiram, em face das limitações verificadas na formação inicial, que era a experiência na 
Novas metodologias na didática da Economia e Contabilidade - caso do Mestrado em Ensino português

lecionação na sala de aula e na universidade, associada à experiência com os pares, que estruturava e imprimia sentido à prática pedagógica dos professores de Ciências Contábeis, confirmada por Carvalho (2017). Ademais, menciona a necessidade de formação contínua (continuada) em face da exigência de práticas pedagógicas, associadas às tecnologias.

Na perspetiva dos alunos, um estudo de Amorim e Bruni (2013) mostrou que os atributos e competências mais importantes que caracterizam um professor de contabilidade são o Domínio de Conhecimento e o da DidáticaPedagógica, seguidos dos atributos relacionados com a Comunicação, Planeamento (Planejamento) e Relacionamento.

Deste modo, constata-se que o incremento da qualidade da formação inicial de professores é um dos fatores fulcrais para o desenvolvimento de um sistema de educação e formação eficaz e eficiente, estando essa preocupação patente nos vários documentos, produzidos por organizações de referência, como a Organização para a Cooperação e Desenvolvimento Económico (OECD, 2015) e a União Europeia (EURYDICE, 2015).

Segundo a Lei em vigor em Portugal (Decreto-Lei n. ${ }^{\circ} 79 / 2014$, de 14 de maio de 2014), que aprova o regime jurídico da habilitação profissional para a docência na educação pré-escolar e nos ensinos básico e médio, só pode exercer a profissão docente quem for portador de um mestrado em ensino, e só pode ter acesso a esse mestrado quem tiver uma licenciatura, ou seja, pelo menos 120 créditos (ECTS) na área da docência específica (graduação).

Ao mestrado, cabe assegurar um complemento da formação do $1^{\circ}$ ciclo de Bolonha, a licenciatura/graduação, que "[...] reforce e aprofunde a formação académica, incidindo sobre os conhecimentos necessários à docência nas áreas de conteúdo e nas disciplinas abrangidas pelo grupo de recrutamento para que visa preparar" (PORTUGAL, 2014, p. 2819). Esses mestrados em ensino devem incluir unidades curriculares na área científica específica de docência, área educacional geral, didáticas específicas, área cultural, social e ética e iniciação à prática profissional.

Assim, as novas exigências em termos de formação inicial de professores do ensino secundário (médio) em Portugal, nomeadamente a organização de mestrados em ensino para as áreas vocacionais, implicaram um conjunto de 
novos desafios nos últimos anos para as instituições de ensino superior que os oferecem, em termos organizacionais, curriculares e culturais.

Em termos gerais, Shulman (1987) já havia identificado alguns dos seguintes elementos constituintes do corpus de conhecimentos que deveriam ser considerados pelos professores: conhecimento dos conteúdos; conhecimento pedagógico geral, incluindo princípios e estratégias para a organização e gestão da sala de aula; conhecimento do currículo, incluindo materiais e programas; conhecimento dos conteúdos pedagógicos; conhecimento dos alunos e das suas características; conhecimento dos contextos educacionais, incluindo as características das turmas, da comunidade e das culturas; conhecimento das finalidades, propósitos e valores educacionais, e das suas bases filosóficas e históricas. Segundo esse autor, compreender como e por que os professores fazem os seus planos de aulas, as teorias implícitas e explícitas que trazem para o seu trabalho e os conceitos da matéria disciplinar que influenciam as suas explicações, orientações, feedback e correções, deveria constituir a característica central da investigação sobre o ensino.

A par dos conhecimentos e competências nucleares, a sociedade contemporânea e a humanidade vivem num novo paradigma tecnológico impulsionado pelas tecnologias de comunicação e informação, também designadas de tecnologias digitais (TD), nomeadamente a Internet que, na visão de Castells (2006), constitui condição facilitadora de uma nova forma de organização social baseada em redes de comunicação digital.

No contexto educativo, segundo o mesmo autor, "[...] difundir a Internet ou colocar mais computadores nas escolas, por si só, não constituem necessariamente grandes mudanças sociais [...]" (CASTELLS, 2006, p. 19), pois essa integração dependerá da forma como tais tecnologias irão ser usadas. Assim, considera-se que um dos aspetos-chave da sociedade em rede será a reconversão total do sistema educativo, com novas formas de relacionar tecnologia e pedagogia, assim como conteúdos e organização do processo de aprendizagem, exigindo-se, concomitantemente, o desenvolvimento de novas metodologias de ensino.

Desta forma, a necessidade de metodologias de ensino inovadoras que permitam uma aprendizagem ativa, associadas à integração pedagógica das TD no ensino em geral, e especificamente no ensino da Economia e da Contabilidade, vem colocar um desafio fundamental aos investigadores da 
Novas metodologias na didática da Economia e Contabilidade - caso do Mestrado em Ensino português

educação e às instituições de formação em face do novo paradigma tecnológico contemporâneo.

\section{Procedimentos metodológicos}

A metodologia de investigação utilizada na componente empírica foi a de estudo de caso, numa abordagem predominantemente qualitativa, suportada na investigação da própria prática, como estratégia de produção de conhecimento e desenvolvimento profissional, devido às autoras do estudo serem docentes de disciplinas do Mestrado em ensino de Economia e de Contabilidade.

A metodologia de estudo de caso é uma abordagem que se adequa à investigação em educação, na medida em que o investigador se confronta com situações complexas nas quais é difícil selecionar variáveis, mas em que se procura descrever e analisar um fenômeno e as suas interações (YIN, 1994). Neste caso, trata-se também de uma investigação sobre uma situação específica, em que se procura descobrir características essenciais visando contribuir para a compreensão global do fenómeno (PONTE, 2006) com maior enfoque

38 na análise dos processos que nos resultados (BOGDAN; BILKEN, 1994).

Sobre a investigação da própria prática, Ponte (2008, p. 177) refere que esta não se reduz ao trabalho de investigação dos professores, mas abrange, principalmente, a reflexão da investigação sobre a sua própria prática, ajudando a compreender os problemas com que eles se deparam como profissionais nas suas instituições, considerando-a "[...] um discurso sobre nós mesmos e a nossa própria prática".

Assim, para a recolha de dados e análise das percepções de futuros professores, foi selecionada uma turma de oito alunos do primeiro ano desse mestrado, no ano letivo de 2016/2017, questionando-os sobre o que é lou deverá) Ser Professor de Economia e de Contabilidade.

Partiu-se de uma questão colocada numa entrevista pelo professor António Nóvoa (2016), solicitando uma reflexão crítica escrita sobre esta. $\bigcirc$ autor defende que não se deve questionar o que os professores precisam saber ou quais conhecimentos devem ter, mas que é preciso que os futuros educadores perguntem: 
[...] como é que eu, pessoa, me formo um profissional, encontrando a minha maneira própria de ser professor, em conjunto com outros profissionais, pesquisando e agindo no espaço institucional da escola, sem nunca esquecer o exercício público da minha profissão? (NÓVOA, 2016).

Para o tratamento das reflexões escritas, anônimas, realizadas pelos mestrandos, foi utilizada a técnica de análise de conteúdo que inclui um conjunto de instrumentos metodológicos que se aplicam a discursos e conteúdos diversificados, numa hermenêutica controlada baseada na dedução e inferência, que permite o cálculo de frequências, através de um sistema de codificação que percorre os dados na procura de regularidades e padrões, visando definir as categorias de codificação, segundo Bardin (2011). Com base nos dados recolhidos, foram definidas as categorias de análise, sendo, posteriormente, apresentados e analisados os respectivos resultados.

Relativamente aos dados da aplicação da metodologia de Formação Ativa, estes foram recolhidos ao longo dos últimos três anos letivos, de 20 1 4-15, 2015-16 e 2016-17, os dois primeiros numa turma de dezessete mestrandos e, no mais recente, numa de oito, do Mestrado em ensino de Economia e de Contabilidade.

Quanto aos instrumentos de recolha de dados, assumiu um papel relevante a observação participante, particularmente devido ao caráter qualitativo impresso a esta investigação, não se descurando nunca a questão de que se deve apresentar o maior rigor na observação e recolha de informação (BOGDAN; BIKLEN, 1994).

Assim, a observação participante ocorreu por meio do registo sistemático de observações e reflexões em notas e relatórios compilados em diários de campo, aproveitando o facto de o investigador ser simultaneamente o docente e estar apto a observar os acontecimentos a todo o instante (BELL, 2008), ou seja, "[...] o investigador foi usado como instrumento de investigação [...]" e de recolha de dados (YIN, 2011 , p. 122).

Os diários de campo foram construídos, seguindo Vierset (2013), como documentos, descrevendo os fatos observados, referindo as questões emergentes em relação a estes e procurando informações através de um processo de reflexão sobre a ação apoiada por argumentos coerentes de acordo com a literatura, visando identificar necessidades e validar aprendizagens que 
Novas metodologias na didática da Economia e Contabilidade - caso do Mestrado em Ensino português

podem ser, posteriormente, usadas na prática letiva ou formativa. Esses diários de investigação constituíram-se em instrumentos essenciais na recolha de dados da observação participante, pois permitiram documentar o processo de abordagem do terreno, as experiências ocorridas e consequentes reflexões (SILVERMAN, 2009).

\section{Ser Professor(a) de Economia e de Contabilidade}

\section{O Mestrado em ensino de Economia e de Contabilidade português}

Atualmente, a Universidade de Lisboa (UL) é a única instituição que em Portugal confere o grau de Mestre em ensino da Economia e da Contabilidade, através do Instituto de Educação (IE), conforme o Regulamento constante no Despacho n 6261, de 11 de abril de 2011 , da Reitoria da UL (PORTUGAL, 20111 .

Nessa instituição, os candidatos aos mestrados em ensino têm de realizar, em primeiro lugar, uma prova de Português, eliminatória e comum a todos os ramos dos mestrados em ensino, sendo, depois, efetuada uma análise curri-

40 cular e de motivação através dos documentos de candidatura e de entrevistas de seleção.

Esse mestrado tem aberto candidaturas de dois em dois anos, tendo-se iniciado como curso de pós-graduação de especialização em ensino da Economia e Contabilidade em 2009, com edições posteriores como Mestrado em ensino da Economia e Contabilidade em 2010-2012, 201 3-20 15 e no período de 201 6-2018, atualmente com a designação de Mestrado em ensino de Economia e de Contabilidade, de acordo com o Despacho n ${ }^{\circ} 7093$, de 26 de junho de 2015 (PORTUGAL, 2015).

- ciclo de estudos de Mestrado em ensino de Economia e de Contabilidade visa proporcionar formação geral e habilitação profissional para a docência no ensino secundário (médio) nas áreas de docência de Economia e de Contabilidade, com uma duração normal do ciclo de estudos de 2 anos, dividido em 4 semestres. $\bigcirc$ último inclui a feitura de um relatório, realizado no âmbito da prática de ensino supervisionada com a respectiva apresentação do ato público de defesa.

Considerando a avaliação como domínio fundamental do conhecimento, nomeadamente visando à melhoria de práticas e procedimentos e 
avaliação de programas (FERNANDES, 2013) foi aplicado, em 2016, um questionário aos antigos, e à época, alunos, de forma a avaliar as anteriores edições do Mestrado em ensino de Economia e de Contabilidade e a extrair informação sobre a sua empregabilidade.

Esse questionário foi enviado para 41 endereços de e-mail tendo-se obtido uma taxa de resposta de 39\%.

Das respostas recebidas, cerca de $35 \%$ referiram-se a alunos que terminaram o mestrado no ano de 2011 , cerca de $20 \%$ em $2012,10 \%$ em $2013,25 \%$ em 2014 e 10\% em 2015.

A grande maioria dos alunos $(81,3 \%)$ tinha já mais de três anos de tempo de serviço, e mais de metade dos alunos $(56,3 \%)$ superavam os 6 anos de serviço docente, o que indicia uma experiência prévia na docência sem qualificação profissional.

Relativamente à questão aberta sobre se o mestrado contribuiu ou poderia vir a contribuir para o seu futuro profissional na docência, as respostas foram claramente afirmativas, com a maioria das referências a incidir no facto de permitir "obter a profissionalização", "adquirir novas competências", "melhorar o desempenho como docente", e ainda "melhorar o nível de acesso ao concurso nacional de professores".

Por fim, relativamente aos alunos que já haviam concluído o mestrado, verificou-se que, até um ano depois de o concluir, cerca de $70 \%$ dos inquiridos obtiveram emprego como docentes ou formadores, cerca de 15\% obtiveram emprego noutra área de atividade, não tendo obtido colocação cerca de 15\% dos mestrandos.

No ano letivo de 2016/2017, iniciou uma nova turma de oito alunos, todos trabalhadores-estudantes, em que apenas dois (25\%) não trabalham na área do ensino e os restantes $75 \%$ lecionam, como técnicos especializados, em cursos profissionais, não podendo lecionar ainda como professores, sem a profissionalização conferida pelo mestrado em ensino, tampouco se candidatar ao concurso nacional de professores do ensino público português.

Deste modo, constata-se a importância desse mestrado, única possibilidade de formação inicial, em Portugal para o acesso à profissionalização docente na área disciplinar de Economia e de Contabilidade. 


\section{Perfil e papel do professor de Economia e Contabilidade}

Considerando o perfil do professor de Ciências Econômicas e Sociais em Portugal (2001), este deverá ser capaz de atuar: na área de docência, nomeadamente dominar os conhecimentos, metodologias e técnicas de trabalho; no currículo, através da análise, avaliação, adaptação e colocação em prática dos currículos, tendo em conta as características específicas dos alunos e o projeto educativo de cada escola; no ensino, com a concepção, planificação, organização e condução do ensino e gestão de situações de ensino-aprendizagem; na avaliação, através da identificação, caracterização, avaliação e comunicação dos resultados da aprendizagem; na participação, nas atividades da escola; e ainda, no desenvolvimento profissional, mantendo-se atualizado sobre os desenvolvimentos em nível científico, do currículo, da investigação educacional e da prática profissional.

Relativamente ao domínio científico, acresce referir a multiplicidade de disciplinas englobadas nesse grupo de recrutamento (Economia e Contabilidade - código 430) no ensino secundário (médio), que inclui áreas como a Gestão, Sociologia e Direito, entre outras afins, além da Economia e da Contabilidade,

42 que se deve à junção em 2006 de dois grupos de recrutamento, os anteriores $6^{\circ}$ e $7^{\circ}$ grupos de docência, Contabilidade e Administração, e Economia, respectivamente (PORTUGAL, 2006).

Verifica-se, assim, uma grande diversidade e exigência colocada ao futuro professor de Economia e Contabilidade, tendo ainda em linha de conta que a iniciação ao estudo da Economia é hoje, no século XXI, indispensável à formação geral do cidadão, qualquer que seja o percurso acadêmico que ele venha a seguir (RODRIGUES, 2012 ).

A título de exemplo, de acordo com o Programa de Economia do ensino secundário (médio) regular, definido pelo Ministério da Educação português, a iniciação ao estudo da Economia permite:

A aquisição de instrumentos fundamentais para o entendimento da dimensão económica da realidade social.

$[\ldots]$

A descodificação e a sistematização da terminologia económica, hoje de uso corrente, sobretudo nos meios de comunicação social. $[\ldots]$ 
O desenvolvimento da capacidade de intervenção construtiva num mundo em mudança acelerada e cada vez mais global, mas onde as decisões a tomar são, quase sempre, nacionais e, muitas vezes, de natureza ou com implicações económicas (SILVA; PASTORINHO; LOPES; SILVESTRE; MOINHOS, 2002, p. 4).

Por outro lado, a lecionação da disciplina de Economia em nível do ensino secundário (médio), sem que exista qualquer outra que the seja introdutória em nível do ensino básico, implica uma dupla função - a de iniciação a uma nova perspetiva científica e a de motivação para a eventual continuação de estudos nesta área.

Desta forma, essa é uma disciplina privilegiada no contributo que pode dar para a formação adequada do aluno finalista do ensino secundário (médio), nomeadamente no domínio do conhecimento e da compreensão do mundo contemporâneo e dos seus principais problemas (RODRIGUES, 2012).

Conforme as finalidades e os objetivos apresentados no Programa de Economia referido, torna-se evidente a necessidade de um processo de ensino-aprendizagem centrado no aluno, um processo ativo que promova a aquisição rigorosa de conhecimentos, incentive o desenvolvimento de competências e de atitudes socialmente úteis e que fomente a autonomia.

De facto, conforme descrito em Silva; Pastorinho; Lopes; Silvestre; Moinhos (2002),

Há maiores possibilidades de aprendizagem nas salas de aula onde existe:

1. Aprendizagem ativa, ou seja, abordagens que encorajam os participantes a implicar-se em oportunidades de aprendizagem.

2. Negociação de objetivos, ou seja, abordagens em que as atividades têm em conta as motivações e interesses de cada participante.

3. Demonstração, prática e reflexão sobre a prática, ou seja, abordagens em que se propõem modelos práticos, se promove a sua utilização e se dão oportunidades de refletir sobre eles.

4. Avaliação contínua, ou seja, abordagens que promovem a investigação e a reflexão como meios de revisão da aprendizagem.

5. Apoio, ou seja, abordagens que ajudam os indivíduos a correr riscos (UNESCO) ISILVA SILVA; PASTORINHO; LOPES; SILVESTRE; MOINHOS, 2002, p. 8). 
Pretende-se, assim, que o aluno construa ou reconstrua os seus saberes e se familiarize com novos métodos de trabalho e, concomitantemente, que o professor de Economia e Contabilidade adquira, na sua formação, conhecimentos e competências técnicas, relacionais e pedagógicas, capazes de enfrentar os novos desafios da educação na sociedade contemporânea.

\section{Novas metodologias de ensino - a Formação Ativa}

A Formação Ativa (FA) constitui-se em uma proposta de uma nova metodologia de formação inicial e contínua (continuada) de professores, apoiada na integração pedagógica das tecnologias digitais (TD) e na inovação das metodologias e estratégias de ensino-aprendizagem associadas. Pretende-se, simultaneamente, adequar ao desenvolvimento profissional e humano, integral e sustentável, dos docentes, no contexto da futura sociedade do conhecimento.

Essa metodologia, que inclui a definição de um método de formação, transversal às áreas curriculares, pressupõe a integração pedagógica das tecnologias digitais em contexto social autêntico, promovendo a sua efetiva experimentação e uso. Carateriza-se por ser organizada à medida dos interes-

44 ses dos formandos, com gestão flexível dos conteúdos, planificação e avaliação partilhada. Utiliza metodologias e estratégias ativas de ensino-aprendizagem, sustentadas numa relação pedagógica afetiva e de base democrática e no trabalho colaborativo e cooperativo em comunidade de aprendizagem, procurando a criação de comunidades de prática e o desenvolvimento e transferência isomórfica de competências, nomeadamente digitais. Tem por base uma perspetiva socioconstrutivista uma vez que advoga a autonomia, a autorregulação, e, ainda, que os professores devem ser os construtores do seu próprio conhecimento e da sua profissionalidade (RODRIGUES, 2017).

Na perspectiva pedagógica, considerando que os modelos de formação devem assentar numa metodologia de cariz colaborativo centrada nos alunos, a metodologia de FA sofreu influência de diversas correntes, com um peso relevante da metodologia do Movimento da Escola Moderna (MEM). Essa assenta num projeto democrático de formação sociocentrada e autoformação cooperada de docentes que pretende transferir a sua estrutura de procedimentos para um modelo de cooperação educativa nas escolas (NIZA, 2012).

Desde Dewey (1960), que preconizou que não pode existir crescimento intelectual ou construção de conhecimento sem reconstrução, tendo a 
educação como fim ideal a criação do autocontrolo, e, também, da autonomia; até Lave e Wenger (1991) que consideram a aprendizagem como um aspecto integral e inseparável da própria prática social, sustentando um dos objetivos da FA que é a criação de comunidades de prática; passando por novas perspectivas, como o modelo TPACK (MISHRA; KOEHLER, 2006), e novas metodologias, caso do trabalho de projeto (KILPATRICK, 2006), em que se pode incluir a aprendizagem pela descoberta e a aprendizagem baseada em problemas (ARENDS, 2008), e da sala de aula invertida ou flipped classroom. Essa última trata-se de uma abordagem inversa ao processo de ensino-aprendizagem no qual se usa a tecnologia para expor, antecipadamente, os alunos a conceitos fora da sala de aula, geralmente através da observação, leitura e análise de textos e vídeos, sendo, posteriormente, o tempo na sala de aula utilizado para compreender esses novos saberes, através da resolução de problemas, discussão ou debates (CARVALHO; RAMOS, 2015).

Salienta-se, ainda, como estratégia de ensino, a discussão em sala de aula, que ocorre quando professores e alunos falam uns com os outros e partilham ideias e opiniões, tendo como objetivos: desenvolver o pensamento dos alunos e ajudá-los a construir os seus próprios significados acerca dos conteúdos; promover o compromisso e o envolvimento dos alunos, responsabilizando-os e proporcionando-lhes oportunidades de falar em público e confrontar-se com as suas próprias ideias; e desenvolver, nos alunos, competências diversificadas, particularmente, competências de comunicação e processos de pensamento (ARENDS, 2008).

Apesar de algumas dessas metodologias não serem propriamente recentes, são referidas como novas, haja vista a sua utilização ter sido muito pontual e não se observa de forma generalizada, procurando a metodologia de FA englobar de forma combinada estas diversas perspectivas de metodologias ativas que permitem a integração das TD no processo de ensino-aprendizagem e a inovação de práticas pedagógicas.

\section{Princípios estruturantes da Formação Ativa}

Tomando por mote "A escola como local de desenvolvimento humano" (PNUD, 2015) e como forma de delimitar e substanciar o conceito e modelo de FA, foram construídos cinco princípios estruturantes, apresentados no Quadro 1 (RODRIGUES, 2017). 


\section{Quadro 1}

Princípios estruturantes da Formação Ativa de professores

\begin{tabular}{|c|}
\hline Princípios estruturantes da FA \\
\hline $\begin{array}{l}\text { Princípio } 1 \\
\text { Modelo de formação transversal às áreas curriculares com integração } \\
\text { pedagógica das tecnologias digitais em contexto social autêntico para o } \\
\text { desenvolvimento humano integral e sustentável. }\end{array}$ \\
\hline $\begin{array}{l}\text { Princípio } 2 \\
\text { Formação organizada à medida das necessidades e interesses dos forman- } \\
\text { dos, diferenciada e centrada nas competências, com planificação e gestão } \\
\text { flexível dos conteúdos. }\end{array}$ \\
\hline $\begin{array}{l}\text { Princípio } 3 \\
\text { Formação baseada numa relação pedagógica democrática e afetiva, com } \\
\text { o formador como orientador, para a reprodução crítica e isomórfica de } \\
\text { competências com os alunos. }\end{array}$ \\
\hline $\begin{array}{l}\text { Princípio } 4 \\
\text { Formação teórico-prática dinâmica, sustentada no trabalho colaborativo e } \\
\text { cooperativo em comunidade de aprendizagem, com a utilização de me- } \\
\text { todologias e estratégias ativas de ensino em sinergia com as tecnologias } \\
\text { digitais. }\end{array}$ \\
\hline $\begin{array}{l}\text { Princípio } 5 \\
\text { Formação para a construção e desenvolvimento de competências de re- } \\
\text { flexividade, autonomia, comunicação em rede, avaliação participada e } \\
\text { autorregulação, para a criação de uma comunidade de prática que permita } \\
\text { a construção social de conhecimento próprio. }\end{array}$ \\
\hline
\end{tabular}

Segundo Rodrigues (2017), a FA de professores pretende ser uma metodologia e, em simultâneo, um método de formação e não a metodologia ou o método de formação. Ou seja, não se pede que os professores usem necessária e exclusivamente esse método, podendo conjugá-lo ou alterná-lo com outros. Pode ser usado para apenas determinado conteúdo ou unidade temática, num período letivo, mas pode ser também utilizado durante todo o ano letivo como método e metodologia dominante.

A utilização de modelos múltiplos, diversificação de métodos e estratégias de aprendizagem permite aumentar os níveis de desempenho dos alunos e obter uma aprendizagem mais eficaz, segundo Arends (2008), podendo o 
professor mudar de método consoante os conteúdos que esteja a lecionar, pelo que haverá partes do programa em que se justificam aulas com uma maior componente expositiva e outras em que poderá ser mais eficaz o recurso ao método interrogativo ou aos métodos ativos. Assim, os métodos deverão ser selecionados de acordo com o tipo de objetivo da aula e conteúdos e o grau de autonomia e de conhecimentos que se pretende que os alunos obtenham (CARDOSO, 2013).

Isto, porque, tal como noutros aspectos do ensino, não se deve assumir uma posição de rigidez e inflexibilidade na utilização de determinado(s) método(s) ou modelo(s), pois, de acordo com Arends (2008), os modelos são guias para pensar e falar sobre o ensino e não devem ser vistos como receitas exatas que possam ser seguidas em quaisquer circunstâncias.

\section{Método da Formação Ativa}

A FA, como metodologia de ensino, possui associada um método de formação específico, na medida em que tenciona também definir um caminho ou modo de "fazer".

De acordo com a Figura 1, seguindo Rodrigues (2017), deve-se partir do currículo ou programa da disciplina, sendo, em primeiro lugar, apresentados aos alunos os domínios e conteúdos a trabalhar. Para tal, são formados grupos ou pares de trabalho e distribuídas as áreas temáticas a abordar, que poderão ser semelhantes, complementares ou diferentes entre os grupos de trabalho consoante o conteúdo ou área temática específica, a trabalhar em forma de metodologia de projeto. 
Figura 1

Método de Formação Ativa de professores

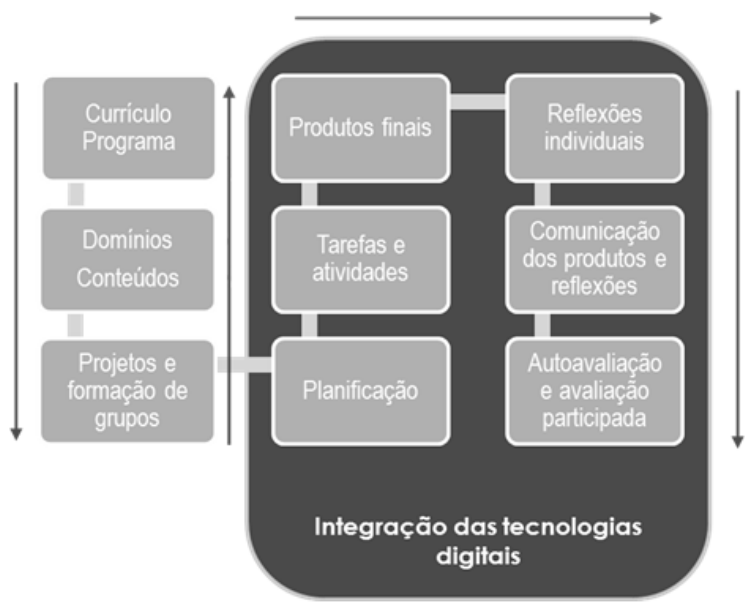

Esse método foi inicialmente aplicado na formação contínua de professores com o desenvolvimento de trabalhos de projeto, contudo, na formação 48 inicial, estes podem assumir formas diversas, nomeadamente com a utilização da metodologia de sala de aula invertida ou flipped classroom e de b-learning, com uma componente presencial significativa e apoio através duma componente on-line, utilizando uma plataforma de gestão de aprendizagens (Learning Management System - LMS).

Nos trabalhos de grupo ou pares, após definição e negociação das atividades a concretizar, cada grupo iniciará a planificação do trabalho com a enumeração e distribuição das tarefas, organização e planeamento do trabalho a realizar. Assim, durante a prática e interação na execução das atividades, seja nas sessões de formação presenciais seja no trabalho não presencial, será prestado apoio e orientação a cada grupo, com a utilização das TD como ferramentas de suporte à aprendizagem e comunicação, através de ensino on-line em forma de b-learning.

Os produtos finais de cada grupo e as reflexões individuais resultantes das atividades desenvolvidas ou trabalhos finais individuais, assim como a comunicação presencial e/ou on-line desses produtos e reflexões, constituirão a base da avaliação sumativa como complemento da avaliação formativa e formadora realizada ao longo do processo de ensino-aprendizagem. A 
avaliação final deverá ainda atribuir uma parcela à autoavaliação e avaliação participada, como forma de reflexão conjunta.

Deste modo, a FA deverá ser considerada também um método privilegiado para a construção e o desenvolvimento de competências de reflexividade, autonomia, comunicação em rede, avaliação participada e autorregulação, a utilizar, através da implementação de metodologias ativas associadas à integração pedagógica das TD, sempre que se considere adequado e exequível relativamente aos objetivos e conteúdos programáticos e considerando recursos tecnológicos disponíveis.

\section{Análise dos resultados}

Quanto às percepções dos futuros professores do mestrado sobre o que é (ou deverá) Ser Professor de Economia e de Contabilidade, seguindo as categorias de análise definidas (definidas no Quadro 2, a seguir), pode-se constatar que, relativamente à primeira categoria, Características e competências do professor, os mestrandos consideraram que um "[...] professor tem de dominar os conhecimentos, metodologias e técnicas de trabalho [...] através do incentivo e motivação" (M8, 2016) devendo, além da licenciatura complementar a sua formação tendo em conta "[...] as metodologias, a pedagogia, a didática $[\ldots]$ " $(M 1,2016)$. Referiram que o trabalho de um professor "[...] exige um planeamento, disciplina e muito trabalho preparatório (e que) a formação é muito importante, mas a atitude perante os alunos é fundamental [...]" (M6, 20 16), devendo o professor "[...] ter caraterísticas de empatia, relacionamento com o grupo, saber científico e capacidade para o expor de forma clara, coerente e pragmática [...]" (M5, 2016) e ainda "[...] conseguir adaptar a aula consoante cada matéria e utilizar outros métodos [...] para cativar os alunos, de forma a que eles tenham mais interesse em aprender" (M7, 2016).

Quanto à categoria Situações, formas e tipos de formação, foram apresentadas pelos mestrandos considerações diversas, nomeadamente, sobre a importância de que "[...] a primeira fonte a que um professor pode recorrer são os livros e/ou artigos". Também foi referida a "[...] produção científica na área da Educação [...]" (M4, 2016), a "[...] importância da educação para a cidadania $[\ldots]$ " $(M 7,2016)$ e da "[...] utilização de metodologias ativas de ensino-aprendizagem" (MI, 2016), assim como de "[...] deixar de ministrar conteúdos teóricos e académicos e transformar os mesmos em conteúdos 
Novas metodologias na didática da Economia e Contabilidade - caso do Mestrado em Ensino português

dinâmicos e aplicáveis na sociedade [...]" (M5, 2016). Foi ainda referido "[...] que será na escola que as pessoas [...] deverão adquirir ou desenvolver competências [...]. Contudo, não chega estar no ambiente escolar, é preciso vivê-lo e experienciá-lo [...]" e "[...] as aulas de mestrado são importantes como ponto de referência" (M1, 2016).

Na categoria Trabalho colaborativo e cooperativo, foram encontradas referências significativas, considerando este como "[...] meio para um professor se formar, [...] e que são os colegas de profissão. A troca de ideias e de experiências [...]" que podem contribuir para a formação da identidade docente, quando "[...] o professor colabora com os seus pares independentemente da disciplina que ensina" (M4, 2016) ou "[...] na transversalidade de conteúdos quer na sua aplicabilidade noutras disciplinas" (M5, 2016).

Nessa categoria, foi, também, referido o fato de que os "[...] alunos não são todos iguais e tem que haver a capacidade de perceber esses pequenos grandes pormenores, ou até conseguir que a turma se ajude entre si $[\ldots]^{\prime \prime}$ (M6, 2016), podendo os alunos e os professores "[...] formar equipas e trabathar em projetos comuns" (M8, 2016).

Quadro 2

Categorias de análise de conteúdo

\begin{tabular}{|c|c|}
\hline Categorias de análise & Exemplos de referências \\
\hline $\begin{array}{l}\text { Características e competên- } \\
\text { cias do professor }\end{array}$ & $\begin{array}{l}\text { "[...] o professor tem de dominar os conhecimentos, metodologias e } \\
\text { técnicas de trabalho" }(M 8,2016) \text {; } \\
\text { "[...] ter caraterísticas de empatia, relacionamento com o grupo, saber } \\
\text { científico e capacidade para expor" (M5, 2016). }\end{array}$ \\
\hline $\begin{array}{l}\text { Situações, formas e tipos de } \\
\text { formação }\end{array}$ & $\begin{array}{l}\text { "[...] importância da utilização de metodologias ativas de ensino-apren- } \\
\text { dizagem" (M1, } 2016) \text {; } \\
\text { "[...] conteúdos dinâmicos e aplicáveis na sociedade" (M5, 2016). }\end{array}$ \\
\hline $\begin{array}{l}\text { Trabalho colaborativo e } \\
\text { cooperativo }\end{array}$ & $\begin{array}{l}\text { "[...] A troca de ideias e de experiências" }(M 4,2016) ; \\
"[\ldots] \text { conseguir que a turma se ajude entre si" }(M 6,2016) ; \\
\text { "...] formar equipas e trabalhar em projetos comuns" }(M 8,2016) \text {. }\end{array}$ \\
\hline $\begin{array}{l}\text { Relação com a comunidade } \\
\text { educativa }\end{array}$ & $\begin{array}{l}\text { "[...] responsabilidade de criar pontes com a vida quotidiana" (M1, } \\
2016) \text {; } \\
\text { "[...] conseguir estabelecer uma relação de confiança com com as } \\
\text { comunidades escolar e extraescolar" (M3, 2016). }\end{array}$ \\
\hline $\begin{array}{l}\text { Identidade docente e desen- } \\
\text { volvimento profissional }\end{array}$ & $\begin{array}{l}\text { "[...] evoluir ao longo da carreira" }(M 2,2016) ; \\
"[\ldots] \text { atualizando os seus conhecimentos" }(M 8,2016)\end{array}$ \\
\hline
\end{tabular}

Quanto à categoria Relação com a comunidade educativa, foi referido que "[...] para além dos alunos, o professor passou a interagir com pais 
e encarregados de educação, todos os profissionais ligados à escola e ainda outros elementos da comunidade [...]" (M4, 2016), passando a não se identificar "[...] a escola como um espaço fechado, muito pelo contrário [...] que será do professor a responsabilidade de criar pontes com a vida quotidiana, com a família, com a realidade social e isto exige capacidade de trabalhar de forma transversal $[\ldots]^{\prime \prime}(M 1,2016)$ e que é

[...] pela procura contínua da forma mais adequada e profícua de conseguir estabelecer uma relação de confiança lque compreende escuta ativa) com os seus alunos e seus familiares, com as comunidades escolar e extraescolar e com todos os que influenciam ou sejam influenciados pela Escola (M3, 2016).

Relativamente à ldentidade docente e desenvolvimento profissional, as referências foram na mesma direção, considerando os mestrandos que "[...] o professor deve também considerar-se ele próprio um "[...] aluno em constante aprendizagem [...]" (M3, 2016), que "[...] deverá evoluir e moldar a sua atuação ao longo da carreira [...]" $(M 2,2016)$ "[...] num processo constante que deverá ser feito, proactivamente $[\ldots]$ ]" $(M 1,2016)$, " [...] a par de novas maneiras e novas metodologias [...]" $(M 6,2016)$ e acompanhando "[...] as constantes mudanças da Sociedade, atualizando os seus conhecimentos" (M8, $2016)$.

Concernente à aplicação da metodologia de Formação Ativa, utilizada na prática pedagógica, ao longo do estudo, obtiveram-se resultados muito positivos, relativos à adequabilidade da metodologia, construção e desenvolvimento de competências e uso de metodologias de ensino-aprendizagem inovadoras.

Partiu-se do programa das disciplinas, sendo, em primeiro lugar, nas aulas presenciais, apresentados aos mestrandos os conteúdos a trabalhar. Seguindo o método proposto, foram formados grupos de trabalho e distribuídas as áreas temáticas, diferentes entre os vários grupos de trabalho, adaptando-se o método às diferentes disciplinas específicas do mestrado.

Nos trabalhos de grupo, os mestrandos efetuaram pesquisa e investigação na Internet, prepararam apresentações, autoscopias e/ou simulações para apresentar em aulas definidas para o efeito e discutir as respectivas temáticas. Noutros casos, foram facultados textos e artigos científicos aos mestrandos para trabalhar em grupo, ler, analisar criticamente, e depois, apresentar 
presencialmente, numa perspetiva de sala de aula invertida. Desta forma, foi privilegiada a discussão sobre os temas, oportunizados momentos de reflexão, de apresentação de trabalhos e de comunicação de resultados entre colegas.

No caso das sessões síncronas on-line, foi também disponibilizado um texto ou artigo científico aos alunos, que o leram antecipadamente para, depois, na sessão de chat ser discutido em conjunto, recorrendo a professora durante a realização da sessão on-line a um guião pré-elaborado com questões e respostas-chave.

Durante a realização e interação na execução das atividades, seja nas aulas presenciais seja no trabalho não presencial de forma on-line, foram prestados pelo docente das disciplinas apoio e orientação a cada grupo.

Outra estratégia utilizada foi a criação de um grupo fechado no Facebook, utilizado como LMS, para comunicação, partilha de materiais e realização das sessões síncronas, com o uso simultâneo do Moodle, mas este essencialmente como repositório de conteúdos.

Adicionalmente, no sentido de reforçar o uso de metodologias ativas, foram solicitados diversos trabalhos de campo e de levantamento sobre o

52 ambiente físico e social e de contacto com alunos e professores nas escolas, com o objetivo de obter dados sobre a natureza do trabalho docente, nomeadamente através da realização pelos grupos de trabalho de inquéritos por questionário e entrevista. Numa das disciplinas, foram, ainda, requeridas a observação e a lecionação de aulas, do professor cooperante de uma escola do ensino secundário (médio), tendo cada mestrando uma escola cooperante adstrita para efetivar o seu trabalho.

Após a aplicação do modelo de Formação Ativa, nomeadamente dos seus princípios estruturantes, nessas turmas de formação inicial de professores, foi possível verificar, designadamente, na primeira (devido à segunda haver iniciado, apenas, no presente ano letivo), um considerável desenvolvimento das competências digitais e da utilização de metodologias ativas. Foi verificado este desenvolvimento nos alunos tanto enquanto alunos do mestrado, como depois, na utilização e integração das tecnologias digitais e metodologias ativas desses professores estagiários nas suas práticas de ensino supervisionado no último ano nas respectivas escolas cooperantes. 


\section{Conclusões}

Com este estudo, desenvolvido entre 2014 e 2017, foi possível constatar que esses futuros professores, a maioria já com experiência profissional no ensino, tem uma ideia consistente e relativamente ampla do que é (ou deverá) Ser Professor(a) de Economia e de Contabilidade.

Em geral, foram identificados alguns dos fatores-chave associados à identidade docente, nomeadamente, a necessidade de os professores possuírem competências diversificadas, em nível dos conhecimentos, pedagogias, metodologias e técnicas, assim como outras em nível da assunção de uma "atitude profissional" que permita a criação de uma boa relação pedagógica e o aumento da motivação dos alunos.

Foi referida não apenas a importância da formação inicial, mas também da experiência e vivência na escola, relacionando os conteúdos teóricos com a sociedade, constatando-se a consciência por parte dos mestrandos da necessidade de utilizar metodologias de ensino inovadoras e de evoluir, proactivamente, no seu futuro processo de desenvolvimento profissional. Reconheceram, ainda, uma visão da escola como local aberto, com necessidade de criação de uma relação de confiança com a comunidade escolar.

Por outro lado, este estudo, permitiu, também, concluir que a grande maioria dos mestrandos demonstrou, sustentada no trabalho colaborativo e cooperativo, uma boa interação na utilização das ferramentas on-line, com a partilha de informações e materiais, e elevada participação, tanto nas aulas presenciais como no trabalho não presencial.

Ademais, verificaram-se a construção e o desenvolvimento de competências dos mestrandos em nível da integração pedagógica das tecnologias associada à inovação das práticas docentes, com o desenvolvimento de atividades com os seus alunos de prática supervisionada que lhes permitiram a transferência isomórfica de competências. Contudo, foi referida, pelos mestrandos, a falta de tempo, como aspecto e argumento mais forte na sua menor disponibilidade para uma maior integração das tecnologias digitais nas suas práticas e simulações de ensino.

Desse modo, conclui-se a aplicabilidade e adequabilidade da metodologia de Formação Ativa de professores, sustentada nos seus princípios estruturantes e método específico, nas disciplinas específicas do Mestrado 
em ensino de Economia e de Contabilidade, com o uso de metodologias inovadoras de ensino-aprendizagem. Assim, pretende-se contribuir para o desenvolvimento pessoal e profissional docente, no contexto da futura sociedade do conhecimento.

Considera-se, assim, o desafio, tal como afirma Garcia (2009), de se procurar

[...] transformar a profissão docente em uma profissão do conhecimento. Uma profissão que seja capaz de aproveitar as oportunidades da nossa sociedade para conseguir que respeite um dos direitos fundamentais: o direito de aprender de todos os alunos e alunas, adultos e adultas (GARCIA, 2009, p. 7).

\section{Referencias}

AMORIM, Paula Florência de Almeira; BRUNI, Adriano Leal. A percepção dos discentes sobre os atributos dos professores - referência no ensino de Contabilidade: um estudo na Faculdade Anísio Teixeira. ReAC - Revista de Administração e Contabilidade, Feira de 54 Santana, v. 5, n. 1, p. 62-73, set./dez. 2013. Disponível em: http://www.fat.edu.br/ reacfat.com.br/index.php/reac/article/view/99/89. Acesso em: 17 maio 2017.

ARENDS, Richard I. Aprender a ensinar. 7. ed. Madrid: Editora McGraw-Hill, 2008.

BARDIN, Laurence. Análise de conteúdo. Lisboa: Edições 70, 2011.

BELL, Judith. Como realizar um projecto de investigação. 4. ed. Lisboa: Gradiva Publicações, 2008.

BOGDAN, Robert; BIKLEN, Sari. Investigação qualitativa em educação. Uma introdução à teoria e aos métodos. Porto: Porto Editora, 1994.

CARDOSO, Jorge Rio. O professor do futuro. Lisboa: Guerra e Paz, 2013.

CARVALHO, Alexandro Farias de. A construção da prática pedagógica dos professores do curso de Ciências Contábeis na educação a distância. 2017. 194f. Dissertação (Mestrado em Educação) - Programa de Mestrado em Educação, Universidade Católica de Santos, Santos, 2017.

CARVALHO, Ricardo Jorge Oliveira; RAMOS, Maria Altina da Silva. Flipped classroom Centrar a aprendizagem no aluno recorrendo a ferramentas cognitivas. In: CONFERÊNCIA 
INTERNACIONAL DE TIC NA EDUCAÇÃO, 9; 2015, Braga. Anais... Braga: Universidade do Minho, 2015. Disponível em: https://repositorium.sdum.uminho.pt/bitstream/1822/35245/1/FLIPPED\%20CLASSROOM\%20\%E2\%80\%93\%20CENTRAR\%20 A\%20APRENDIZAGEM\%2ONO\%20ALUNO.pdf. Acesso em: 15 abr. 2017.

CASTELLS, Manuel Oliván. A sociedade em rede: do conhecimento à política. In: CASTELLS, Manuel; CARDOSO, Gustavo (Org.). A sociedade em rede. Do conhecimento à acção política. Portugal: Imprensa Nacional Casa da Moeda, 2006.

DEWEY, John. Experiencia y educación. Buenos Aires: Editorial Losada, S.A, 1960.

EURYDICE. The teaching profession in Europe: practices, perceptions, and policies. Eurydice Report/Commission/EACEA. Luxembourg: Publications Office of the European Union, 2015. Disponível em: http://eacea.ec.europa.eu/education/eurydice/documents/thematic_ reports/184EN_HI.pdf. Acesso em: 22 maio 2017.

FERNANDES, Domingos Manuel Barros. Avaliação em educação: uma discussão de algumas questões críticas e desafios a enfrentar nos próximos anos. Ensaio, Rio de Janeiro, v. 21, n. 78, p. 11-34, jan./mar. 2013. Disponível em: http://www.scielo.br/scielo. php? script=sci_arttext\&pid=S0 104-40362013000100002. Acesso em: 20 jan. 2017.

GARCIA, Carlos Marcelo. A identidade docente: constantes e desafios. Revista Formação Docente, Belo Horizonte, v. 1, n. 1, ago./dez. 2009. Disponível em: http://formacaodocente.autenticaeditora.com.br/artigo/exibir/1/3/2. Acesso em: 20 maio. 2017.

KILPATRICK, William Heard. 0 método de projecto. Viseu: Livraria Pretexto e Edições Pedago, 2006.

LAVE, Jean; WENGER, Etienne Charles. Situated learning: legitimate peripheral participation. Cambridge: Cambridge University Press, 1991.

M1 (Mestrando 1). Reflexão escrita. Lisboa (Portugal), 29 set. 2016.

M2 (Mestrando 2). Reflexão escrita. Lisboa (Portugal), 29 set. 2016.

M3 (Mestrando 3). Reflexão escrita. Lisboa (Portugal), 29 set. 2016.

M4 (Mestrando 4). Reflexão escrita. Lisboa (Portugal), 29 set. 2016.

M5 (Mestrando 5). Reflexão escrita. Lisboa (Portugal), 29 set. 2016.

M6 (Mestrando 6). Reflexão escrita. Lisboa (Portugal), 29 set. 2016.

M7 (Mestrando 7). Reflexão escrita. Lisboa (Portugal), 29 set. 2016. 
Novas metodologias na didática da Economia e Contabilidade - caso do Mestrado em Ensino português

M8 (Mestrando 8). Reflexão escrita. Lisboa (Portugal), 29 set. 2016.

MIRANDA, Gilberto José; NOVA, Silvia Pereira; JÚNIOR, Edgard Bruno. Os Saberes dos Professores-Referência no Ensino de Contabilidade. Revista Contabilidade \& Finanças, São Paulo, v. 23, n. 59, p. 142-153, maio/ago. 2012. Disponível em: http://dx.doi. org/10.1590/S1519-70772012000200006. Acesso em: 17 maio 2017.

MISHRA, Punya; KOEHLER, Matthew J. Technological pedagogical content knowledge: a framework for teacher knowledge. Teachers College Record, Calumbia, v. 108, n. 6, p. 1017-1054, june 2006. Disponível em: http://one2oneheights. pbworks.com/f/MISHRA_ PUNYA.pdf. Acesso em: 12 dez. 2016.

NIZA, Sérgio. Uma democracia participada na escola: a gestão cooperada do currículo. In: NÓVOA, António; MARCELINO, Francisco; Ó, Jorge Ramos do. (Coord.). Sérgio Niza. Escritos sobre educação. Lisboa: Movimento da escola moderna e Edições Tinta-da-china, Lda, 2012.

NÓVOA, António Manuel Seixas Sampaio da. Entrevista: Formação docente deve incentivar trabalho colaborativo. São Paulo. 31 de agosto de 2016. hitp://porvir.org/formacao-docente-deve-incentivar-trabalho-colaborativo/. Acesso em: 12 dez. 2016.

56 OECD. Education ate a Glance Interim Report, 2015. Retrieved from http://www.oecd. org/edu/innovation-education. Acesso em: 12 dez. 2016.

PNUD. Work for Human Development. Human Development Report 2015, United Nations Development Programme, 2015. Disponível em: http://report.hdr.undp.org. Acesso em: 12 dez. 2016.

PONTE, João Pedro da. Estudos de caso em educação matemática. Bolema, Rio Claro, v. 19, n. 25, p. 105-132, jan./jun. 2006. Disponível em: http://repositorio.ul.pt/ bitstream/10451/3007/1/06-Ponte(BOLEMA-Estudo\%20de\%20caso).pdf. Acesso em: 20 jan. 2017.

Investigar a nossa própria prática: uma estratégia de formação e de construção do conhecimento profissional. PNA, Granada, v. 2, n. 4, 153-180, 2008. Disponível em: http://www. pna.es/Numeros2/pdf/Ponte2008PNA2(4)Investigar.pdf. Acesso em: 20 jan. 2017.

PORTUGAL. Decreto-Lei n. 240 , de 30 de agosto de 2001 . Perfil do professor de Ciências Económicas e Sociais. Diário da República, Lisboa, n. 201, Série 1-A, p. 5569-5571. 
Decreto-Lei n. ${ }^{\circ} 27$, de 10 de fevereiro de 2006. Grupos de recrutamento para efeitos de seleção e recrutamento do pessoal docente. Diário da República, Lisboa, n. 30, Série 1-A, p. 1095-1099.

. Decreto-Lei n. $79 / 2014$ de 14 de maio de 2014. Regime jurídico da habilitação profissional para a docência na educação pré-escolar e nos ensinos básico e secundário. Diário da República, Lisboa, n. 92, Série 1, p.2819-2828.

Despacho n. 6261/2011, 11 de abril de 2011. Reitoria da Universidade de Lisboa. Regulamento do Mestrado em Ensino da Economia e Contabilidade. Diário da República, Lisboa, n. 71, Série 2, p. $16813-16818$.

Despacho n. 7093, 26 de junho de 2015. Alteração de Ciclo de Estudos /da designação) de Mestrado em Ensino de Economia e de Contabilidade. Diário da República, Lisboa, n. 123, Série 2, p.17245-17247.

RODRIGUES, Ana Luísa Pinto da Fonseca. O papel das novas tecnologias para a aprendizagem autónoma e a criação de conhecimento com base em pedagogias construtivistas na disciplina de economia A. 2012. Dissertação (Mestrado em Ensino da Economia e Contabilidade) - Universidade de Lisboa, Lisboa, 2012.

A formação ativa de professores com integração pedagógica das tecnologias digitais. 2017. Tese (Doutorado em Educação) - Universidade de Lisboa, 2017.

SHULMAN, Lee S. Knowledge and teaching: Foundations of the new reform. Harvard Educational Review, Cambridge, v. 57, n. 1, 1-21, 1987. Disponível em: https://people. ucsc.edu/ ktellez/shulman.pdf. Acesso em: 12 dez. 2016.

SILVA, Elsa (Coord); PASTORINHO, António; LOPES, Lúcia; SILVESTRE, Manuela; MOINHOS, Rosa. Programa de Economia A. Lisboa: Departamento do Ensino Secundário/Ministério da Educação, 2002. Disponível em: https://www.dge.mec.pt/sites/default/files/ Secundario/Documentos/Programas/economia_a_10_11.pdf. Acesso em: 12 dez. 2016.

SILVERMAN, David. Interpretação de dados qualitativos: métodos para análise de entrevistas, textos e interações. Porto Alegre: Artmed, 2009.

SLOMSKI, Vilma Geni; LAMES, Edilei Rodrigues de; MEGLIORINI, Evandir; LAMES, Liliane da Costa Jacobs. Saberes que fundamentam a prática pedagógica do professor que ministra a disciplina de gestão de custos em um curso de Ciências Contábeis. Revista Universo Contábil, Blumenau, v. 9, n. 4, p. 71-89, out./dez. 2013. Disponível em: http://proxy. furb.br/ojs/index.php/universocontabil/article/view/585/2529. Acesso em: 17 maio 2017. 
VIERSET, Viviane. Le log book: un support d'apprentissage, d'accompagnement et d'évaluation des compétences professionnelles. Bulletin de I'ADMEE, Neuchâtel, n. 3, p. 4-18, 2013. Disponível em: http://pedagogie-universitaire.blogs.usj.edu.lb/files/2013/11/BulletinAdmee-2013-3.pdf. Acesso em: 12 dez. 2016.

YIN, Robert K. Case study research: design and methods. 2. ed. Thousand Oaks, CA: SAGE Publications, 1994.

YIN, Robert K. Qualitative research from start to finish. New York: The Guilford Press, 2011.

Prof. Dra. Ana Luísa Rodrigues Universidade de Lisboa | Portugal Instituto de Educação Grupo de Investigação de Políticas de Educação e Formação E-mail | alrodrigues@ie.ulisboa.pt

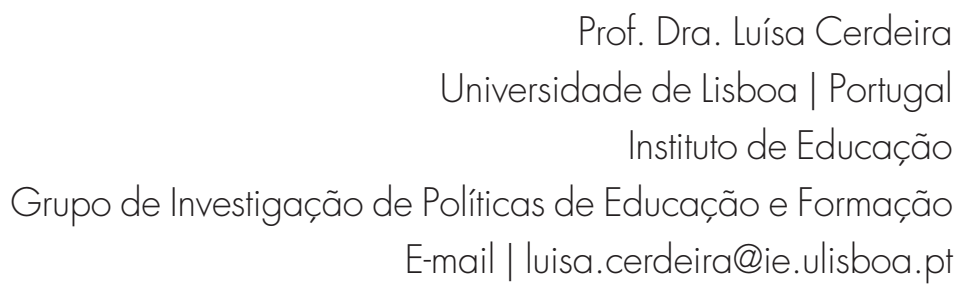

Recebido $1^{\circ}$ ago. 2017

Aceito 9 out. 2017 